\title{
Experimental Study of Oil Pipeline Leak Processes
}

\author{
Agbakwuru Ahamefula Jasper', Gudmestad Tobias Ove ${ }^{1}$, Bilstad Torleiv² \\ ${ }^{1}$ Department of Offshore Engineering, University of Stavanger, Stavanger, Norway; ${ }^{2}$ Department of Environmental Engineering, \\ University of Stavanger, Stavanger, Norway. \\ Email: jasper.agbakwuru@uis.no
}

Received April 17 ${ }^{\text {th }}$ 2012; revised May 19 ${ }^{\text {th }}, 2012$; accepted June $4^{\text {th }}, 2012$

\begin{abstract}
This work provides a description of oil leak/spill processes from containment such as pipeline. Understanding of such processes is important in order to adequately estimate oil spills and to justify an appropriate emergency action for minimizing spills. Internal diameters of pipes used in the study are within 4 inches. Leaks are simulated from plastic pipeline oil containment fitted with valves. The leak response with time when upstream and downstream valves are operated is studied. Within the internal diameters of pipelines considered in the tests, two ranges of leak characteristics are evident; the "holding range" and the "flowing range" characteristics. The consequences of these characteristics in the oil industry operations have been discussed. The work suggests a spill estimation method based on this knowledge. Furthermore, in order to minimise spill in event of pipeline failure, it is observed that the optimum action on pipeline operational valves, is the immediate closure of upstream valve, followed by the downstream valve, nearly simultaneously. Future work will extend the test to larger diameter pipelines to attempt developing a mathematical approach for estimating limits of the "holding range" characteristics of pipelines given appropriate parameters and in-field test.
\end{abstract}

Keywords: Oil Spill; Oil Leak; Pipeline; Downstream Valve; Upstream Valve; Early Leak Event

\section{Introduction}

It is important to understand leak processes from oil pipelines and the manner leaks respond when associated valves are actuated. This is to enable better technique of spill control and volume estimation.

The United State's Department of Transportation Pipeline and Hazardous Materials Safety Administration reports from the ExxonMobil Pipeline Company (ExxonMobil) oil spill in Laurel, Montana on July 1, 2011. "ExxonMobil shut down the pumps at Silvertip station. At approximately 10:57 p.m., the company closed the Laurel block valve located downstream of the failure site. Thereafter, ExxonMobil reopened the block valve at 11:07 p.m. and closed it at 11:28 p.m. MDT. ExxonMobil closed the block valve located upstream of the failure site at approximately 11:36 p.m. MDT. This valve shuts down the flow of product into the Yellowstone River" [1]. Shell Nigeria quotes the procedure for Shell Nigeria responses to spills: "SPDC's operators continuously monitor for leaks and respond to anomalies. In addition, any report, either by community surveillance teams under contract to SPDC or by the public, are responded to immediately. SPDC first shuts down the flow of oil to the leak before steps are taken to verify other details about the incident in preparation for the response, which starts with containment. By immediately shutting down pipelines or flow-lines that are damaged and containing the spills, we minimize the damage to the environment" [2].

It is noted that in line with US Department of Transportation Standards for emergency response for pipeline facilities, the immediate action under all circumstances is to isolate the leaking section of the pipeline, i.e. to activate the ESD valve upstream and any intermediate valves upstream/downstream of the leakage point [3]. PHMSA, an Office of Pipeline Safety (OPS) administers the national regulatory program to ensure safe transportation of hazardous liquids, including crude oil in pipelines in the United States of America.

ASME B31.4 section 454 puts the pipeline leak emergency action as:

1) Reduction of pipeline pressure by ceasing pumping operations for the piping system.

2) Opening the system to delivery storage on either side of the leak site.

3) Expeditious closing of block valves on both sides of the leak site.

The description of the valve operation in the cases discussed above provides a dilemma of what ought to be the optimum methodology in the upstream/downstream 
operation in event of oil spills. The reason the discussion is crucial is because it is important to respond correctly in oil pipeline spill situations. Action, when properly executed, is believed to contribute to minimal oil leaks.

The manners and techniques for which pipeline operators handle spill emergencies could determine the extent of oil pollution to the environment. The main action required in an event of oil pipeline spill is shutting down the pressure supply. This activity often involves the closure of the upstream and downstream valves.

It is important to establish via experimentation the optimum valve adjustment to minimise spill of oil from oil pipelines in the event of pipeline failures. The outcome could be relevant to the aspect of oil spill emergency handling as a requirement of risk analyses and management of pipeline operation including emergency planning and procedures.

Foremost detailed documentation in literature related to this study is provided as in [4-6]. Though the authors provided great insight in the subject and the theories are useful, it is however noted that the theories appear to have paid much attention to cases of "guillotine" break of pipelines where at time zero the pipeline is cut into two. This is in such a way that the flow from each end is free and unobstructed. In reality, the break is often not into two parts, but a partial break off or opening of the barrier between the two fluids of different densities: Oil and air for land pipelines or oil and water for subsea pipelines. The partial break/opening of barriers is often "throughhole" damage to pipe structure itself due to corrosion, structural or third party damages [7].

Concern is also on what ought to be the method for estimating spills from oil pipelines. Some spill estimations are made based on time intervals between when the abnormal change in pressure is detected and the time the pipeline is shutdown. For instance, Exxon-Mobil estimated the oil spill in Montana's Yellowstone River at 1000 barrels from the six-minutes it took from the time of detection of the pressure drop and to the time the pipeline was shut down [8]. By pipeline shut-down, it is understood as stoppage of the oil pump or other pressure supply system and including valves.

\subsection{Leak/Spill Process}

Based on references [5,6], five main processes responsible for spills when pipeline failure occurs could be deduced.

1) Shutdown loss: This is the loss of oil due to operational lag time between when the containment barrier is broken and the time the pressure supply system is shut down. It could be calculated from the time taken to shut down the pump multiplied by the flow-rate through the opening on the pipeline structure.

2) Contraction loss: This is due to the elastic contraction of the pipeline. The oil is squeezed out of containment.
3) Expansion loss: Expansion of oil content (in line with the bulk modulus theory) due to reduction in pressure. This leads to further squeeze out of oil. The larger the gas content of the oil, the more the expansion loss.

4) Head loss: This is due to positive pressure difference between the containment column and the containment broken point. The head loss is considered to play a significant role in losses of types 1, 2, 3 and 5 .

5) "Late phase" leak: After the initial wave processes (introduced by the inertia of the pumping flows, contraction and expansion) have subsided, the pipeline will tend to be in pressure equilibrium with the surroundings. The slow intrusion wave will continue to drive out oil, but at a decreasing rate. For large diameter and long distance pipelines, this process can last for days unless corrective actions are taken. Unlike the first four processes which are governed by the gravity and inertia forces, the late phase loss is dominated by gravity and viscosity as discussed in $[5,6]$.

In this work, however, due to absence of mechanical pressure system, shutdown loss is absent.

\subsection{Spill/Leak Estimation}

Efforts have been made by various authors to model oil/ gas plume for spill management and predictions. Plume as referred to in [9-13] rely on certain pressures within the system to exit from the pipeline. The present work, however, is looking at the events in the "late phase" leak described in $[5,6]$. Reference is made to an opening on pipeline structure and closure of upstream and downstream valves to isolate flow, rather than a complete break of oil pipeline. The description of "late phase" as in $[5,6]$ is the phase of the leak resulting from exchange flow between oil/gas and the environment. Intrusion loss is the most serious for line carrying stabilized crude, especially for long distance and relatively large diameter pipelines. This case is the drive for this study.

\subsection{Scope and Objective}

There is perhaps a clear understanding of loss type 1 which depends on the emergency response system. Types 2 and 3 are often classified as "early phase" events and are documented adequately in [5,6,14]. However, better understanding is required on 4 and 5 events. The objective of this work is to understand the process of leaks for a leaking pipeline and the optimum response in order to minimize spills. It is hoped that such knowledge will enable accurate spill estimation.

\section{Method and Materials}

The following apparatus and items were used in the laboratory testing at the University of Stavanger:

1) Clock watch; 
2) 3/8", 1", 2", 3" and 4" pipes;

3) Drilling machine and drill bits (various sizes);

4) Raw crude oil (density is calculated);

5) Oil collection basin;

6) Weighing machine;

7) Spill containers;

8) Stop watch;

9) Meter rule.

A pipeline running between two risers and the leak occurring at the horizontal part of the pipeline were considered. Raw crude oil is provided and made to flow through the set-up as in Figures $\mathbf{1}$ and 2. The scenario is made as realistic as possible.

Holes of different sizes are made to verify the leak responses when the pipeline leaking section is isolated by valves. The study begins on "land" environment and the critical responses are then tested in the underwater (marine) environment. The isolation will also be broken by keeping one valve in open position at a time to observe the consequences. In this work, leak or rupture of an oil pipeline is regarded as pipeline incapacitation to contain its content resulting to uncontrolled spill of the oil to the environment. Again, pipeline refers to the pipeline structure running on or below the ground or subsea bottom. The laboratory set-up for the testing is shown in Figures 1 and 2.

1) The density of the given raw crude oil is calculated in the laboratory:

Mass of beaker + oil $=0.3445 \mathrm{~kg}$

Mass of beaker $=0.2740 \mathrm{~kg}$

Oil mass $=0.0705 \mathrm{~kg}$

Volume of oil in the beaker $=0.1$ litre $=0.0001 \mathrm{~m}^{3}$.

Therefore, density of the crude $=$ mass $/$ volume $=705$ $\mathrm{kg} / \mathrm{m}^{3}\left(20^{\circ} \mathrm{C}\right)$.

2) Prepare the pipelines with upstream and downstream valves.

3) Starting from the 1" pipe, set up the pipeline as shown in Figure 2 and make a hole of $1 \mathrm{~mm}$ on the horizontal part of the pipeline starting at 3-O'clock position between the two valves. The $1 \mathrm{~mm}$ hole represents a pin hole.

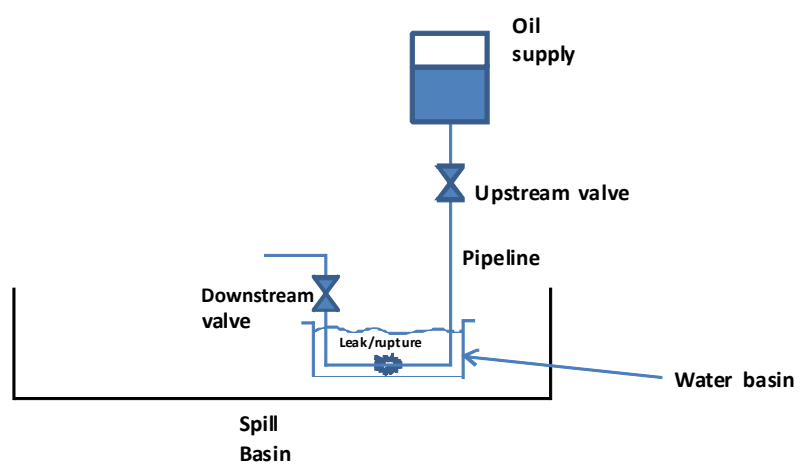

Figure 1. Test of leakage in water.

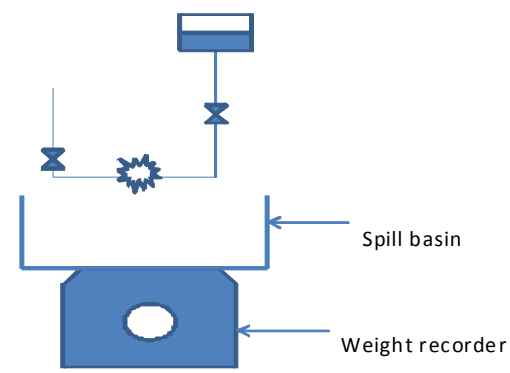

Figure 2. General test set-up (onshore).

4) Fill up the pipeline with oil through the upstream end while keeping the hole and the last downstream valve closed.

5) Shut the upstream valve, open the hole and observe the oil leak through the drilled hole.

6) Observe the characteristics and record the spill in a given time.

7) Increase the hole to next size till appreciable difference in leakage behavior is observed. Record the spill in a given time for each case. (Caution: Drill-outs from the hole drilling operation will tend to clog the hole. Ensure to clear the drill-outs before each test).

8) Change the clock position on the pipeline and repeat the test.

9) Switch to the 2" pipeline and repeat the same at the 6-O'clock position.

10) Switch to the 3 " and 4" pipelines and repeat the same at the 3-O'clock position.

11) Switch to $3 / 8$ " pipe to verify the surface tension.

\section{Results and Analysis}

The results are in Tables $\mathbf{1}$ and $\mathbf{2}$.

The plots to analyze the results are also shown in Figures 3 and 4 .

\section{Discussion}

1) Within the sizes of pipelines considered in the tests, two ranges of leak characteristics are evident:

- The "holding range" characteristics;

- The "flowing range" characteristics.

This behavior can be generalized as in Figure $\mathbf{5}$.

2) The larger the diameter, the more oil in the pipeline, the greater the amount of the "early phase" leaks (Table 1).

3) The limit of "holding range" is between $6 \mathrm{~mm}$ to 8 $\mathrm{mm}$ for the pipelines tested.

4) The limit of "holding range" hole size appears to decrease with increase in pipe size, implying that for pipelines beyond 4", one could expect the limit to be lower than $8 \mathrm{~mm}$ diameter hole.

5) The limit of the "holding range" does not vary with hole's (clock) position of the pipeline (Table 2). 
Table 1. Leak characteristics of various pipe sizes.

\begin{tabular}{|c|c|c|c|c|}
\hline \multirow{2}{*}{$\begin{array}{l}\text { Leaking hole diameter } \\
\qquad(\mathrm{mm})\end{array}$} & \multicolumn{4}{|c|}{ Mass of oil discharged per unit time (kg/min) } \\
\hline & $\begin{array}{l}\text { 1" pipe, 6-O'clock position: } \\
68 \mathrm{~cm} \text { oil column }\end{array}$ & $\begin{array}{l}\text { 2” pipe, 6-O'clock position: } \\
80 \mathrm{~cm} \text { oil column }\end{array}$ & $\begin{array}{l}\text { 3” pipe, 3-O’clock position: } \\
100 \mathrm{~cm} \text { oil column }\end{array}$ & $\begin{array}{l}\text { 4" pipe, 3-O'clock position: } \\
90 \mathrm{~cm} \text { oil column }\end{array}$ \\
\hline 2 & $0.0004^{*}$ & $0.0054^{*}$ & $0.0085^{*}$ & $0.0245^{*}$ \\
\hline 2.5 & $0.0001^{*}$ & - & - & - \\
\hline 3 & $0.0002^{*}$ & $0.0012^{*}$ & - & - \\
\hline 3.5 & $0.0001^{*}$ & - & - & $0.0568^{*}$ \\
\hline 4 & $0.0002^{*}$ & $0.0018^{*}$ & $0.0176^{*}$ & - \\
\hline 4.5 & $0.0003^{*}$ & - & - & - \\
\hline 5 & $0.0001^{*}$ & - & - & $0.0546^{*}$ \\
\hline 5.5 & - & $0.0058^{*}$ & - & - \\
\hline 6 & $0.0002^{*}$ & $0.0036^{*}$ & $0.0185^{*}$ & - \\
\hline 6.5 & - & - & - & - \\
\hline 7 & $0.0005^{*}$ & $0.0062^{*}$ & $0.034^{*}$ & $0.0761^{*}$ \\
\hline 7.5 & $0.0001^{*}$ & - & - & - \\
\hline 8 & $0.0005^{*}$ & 0.137 & 0.1332 & - \\
\hline 8.5 & 0.0997 & - & - & - \\
\hline 9 & 0.1676 & 0.2167 & 0.1985 & 0.1974 \\
\hline 9.5 & 0.1625 & - & - & - \\
\hline 10 & 0.2391 & - & - & - \\
\hline 10.5 & - & - & - & - \\
\hline 11 & - & - & - & - \\
\hline 11.5 & 0.5318 & - & - & - \\
\hline 12 & - & - & 0.2948 & 0.4493 \\
\hline 12.5 & 0.5528 & - & - & - \\
\hline 13 & - & - & - & - \\
\hline 13.5 & - & - & - & - \\
\hline 14 & 0.657 & - & - & - \\
\hline
\end{tabular}

${ }^{*}$ Hole size of pipeline within the holding range.

6) The limit of the "holding range" for a given pipeline tested does not alter with variation in oil column (Figure 4). However, at higher oil column, deviation from the holding range appears to occur exponentially (Figure 4).

7) Within the "holding range", only the "early phase" leak occurs (leak types 2 and 3), provided the downstream and upstream valves are closed.

8) The "early phase" leak occurs independent of the size of the hole, but disappears as quickly as the wave processes (initial momentum introduced as a result of the leakage) discontinue.
9) On the other hand, within the "flowing range" the intrusion of air begins immediately following the elapse of the "early phase leak". Oil naturally "flows or drain" out of the pipeline.

10) The "early phase" leak occurs within seconds.

11) The leak type 4 affects the amount of spill in the early phase of 2 and 3 (Table 2) but it does not continue to thrive after the wave processes are over. The column height only increases the early leak. The range characteristic is unaffected.

12) Leak type 5 does not occur in the "holding range".

13) Openings on the pipeline within the "flowing 
Table 2. Comparing leak characteristics for varying oil column.

\begin{tabular}{|c|c|c|c|c|}
\hline \multirow{2}{*}{$\begin{array}{l}\text { Leaking hole diameter } \\
\qquad(\mathrm{mm})\end{array}$} & \multicolumn{4}{|c|}{ Mass of oil discharged per unit time (kg/min) } \\
\hline & $\begin{array}{l}\text { 1" pipe, 6-O'clock position: } \\
170 \mathrm{~cm} \text { oil column }\end{array}$ & $\begin{array}{l}\text { 1" pipe, 3-O'clock position: } \\
170 \mathrm{~cm} \text { oil column }\end{array}$ & $\begin{array}{l}\text { 1" pipe, 3-O'clock position: } \\
68 \mathrm{~cm} \text { oil column }\end{array}$ & $\begin{array}{l}\text { 1” pipe, 6-O'clock position: } \\
68 \mathrm{~cm} \text { oil column }\end{array}$ \\
\hline 2 & $0.0006^{*}$ & $0.001^{*}$ & - & $0.0004^{*}$ \\
\hline 2.5 & - & - & - & $0.0001^{*}$ \\
\hline 3 & $0.0013^{*}$ & $0.0008^{*}$ & $0.0006^{*}$ & $0.0002^{*}$ \\
\hline 3.5 & - & - & - & $0.0001^{*}$ \\
\hline 4 & $0.0017^{*}$ & $0.0007^{*}$ & - & $0.0002^{*}$ \\
\hline 4.5 & - & - & $0.0007^{*}$ & $0.0003^{*}$ \\
\hline 5 & $0.0018^{*}$ & $0.001^{*}$ & $0.0007^{*}$ & $0.0001^{*}$ \\
\hline 5.5 & - & $0.0007^{*}$ & - & - \\
\hline 6 & $0.001^{*}$ & $0.0007^{*}$ & $0.0009^{*}$ & $0.0002^{*}$ \\
\hline 6.5 & - & - & - & - \\
\hline 7 & $0.0004^{*}$ & $0.0029^{*}$ & $0.0015^{*}$ & $0.0005^{*}$ \\
\hline 7.5 & - & - & - & $0.0001^{*}$ \\
\hline 8 & $0.0017^{*}$ & - & $0.0006^{*}$ & $0.0005^{*}$ \\
\hline 8.5 & 0.0157 & 0.058 & 0.134 & 0.0997 \\
\hline 9 & 0.073 & 0.127 & 0.153 & 0.1676 \\
\hline 9.5 & - & - & - & 0.1625 \\
\hline 10 & 0.076 & 0.1667 & - & 0.2391 \\
\hline 10.5 & - & - & - & - \\
\hline 11 & - & - & - & - \\
\hline 11.5 & - & - & - & 0.5318 \\
\hline 12 & 0.237 & 0.445 & - & - \\
\hline 12.5 & - & - & - & 0.5528 \\
\hline 13 & 1.088 & 2.7888 & 0.604 & - \\
\hline 13.5 & - & - & - & - \\
\hline 14 & - & - & - & 0.657 \\
\hline
\end{tabular}

*Hole size of pipeline within the holding range.

Range” will continue to leak after the "early phase" leak till complete drain of the oil from the line or equilibrium is reached. The more the oil column in the riser, the faster the leakage (Figure 4).

14) Within the "holding range", the closure of both downstream and upstream valves shuts the release to the environment. The only evident leak is the "early phase" leak due to the wave process.

15) However, if any of the valves are left fully or partially open (downstream or upstream), "decaying leak" continues at rates proportional to the hydrostatic head. The oil is observed to be leaking naturally.

\section{Testing in Water Environment}

The results obtained from the tests were used to study the behavior in underwater conditions:

1) Water does not intrude into the pipelines for openings within the holding range. On the other hand, intrusion process in line with the theory as in $[5,6]$ were evident for opening within the "flowing range" (Table 3).

In an attempt to verify the possibility of two holes within the holding range, interacting to behave like a "flowing range" hole, two holes within the "holding range" were made and tested (Table 4).

2) The behavior of the leaks in water follows similar 


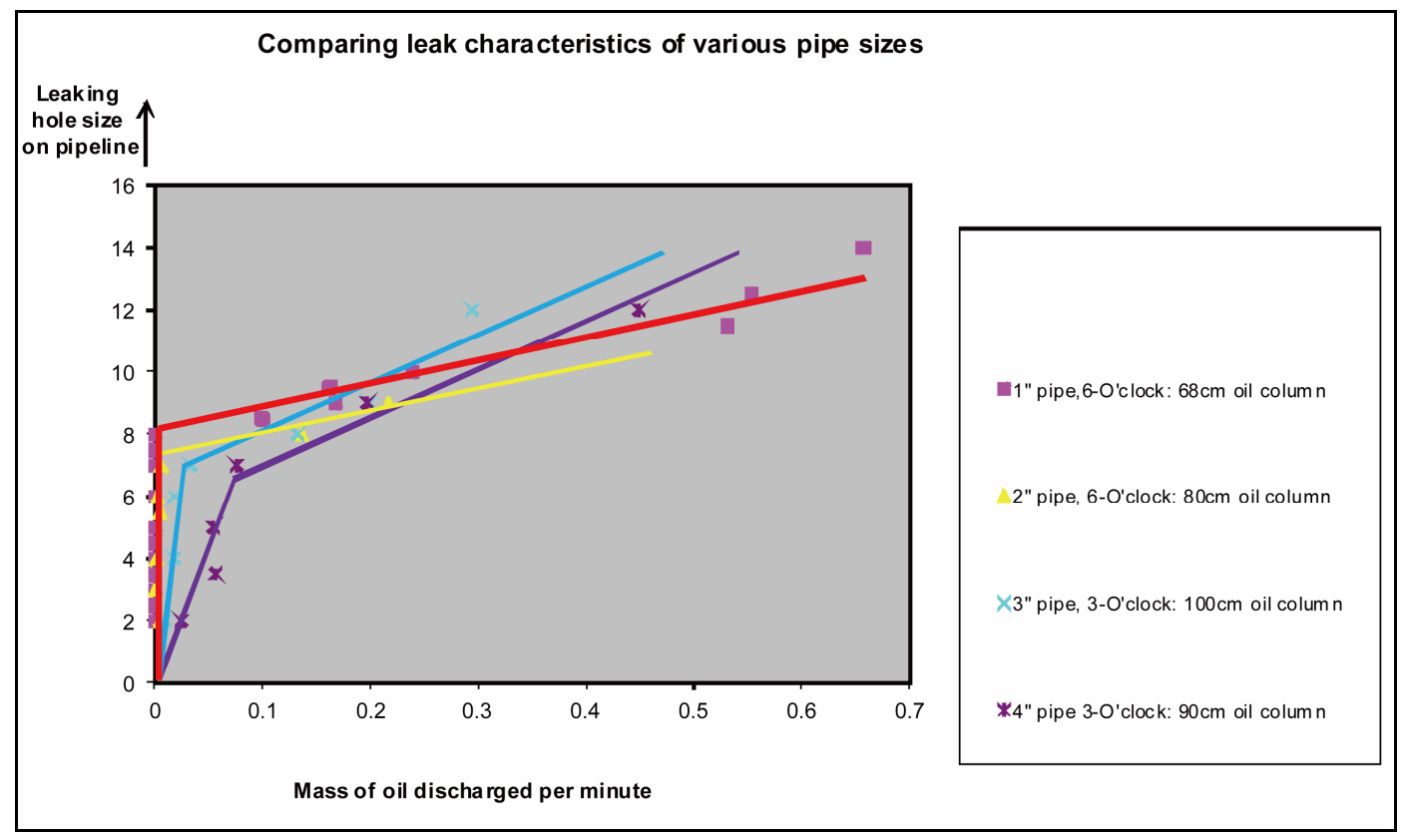

Figure 3. Plot of leak characteristics of various pipe size.

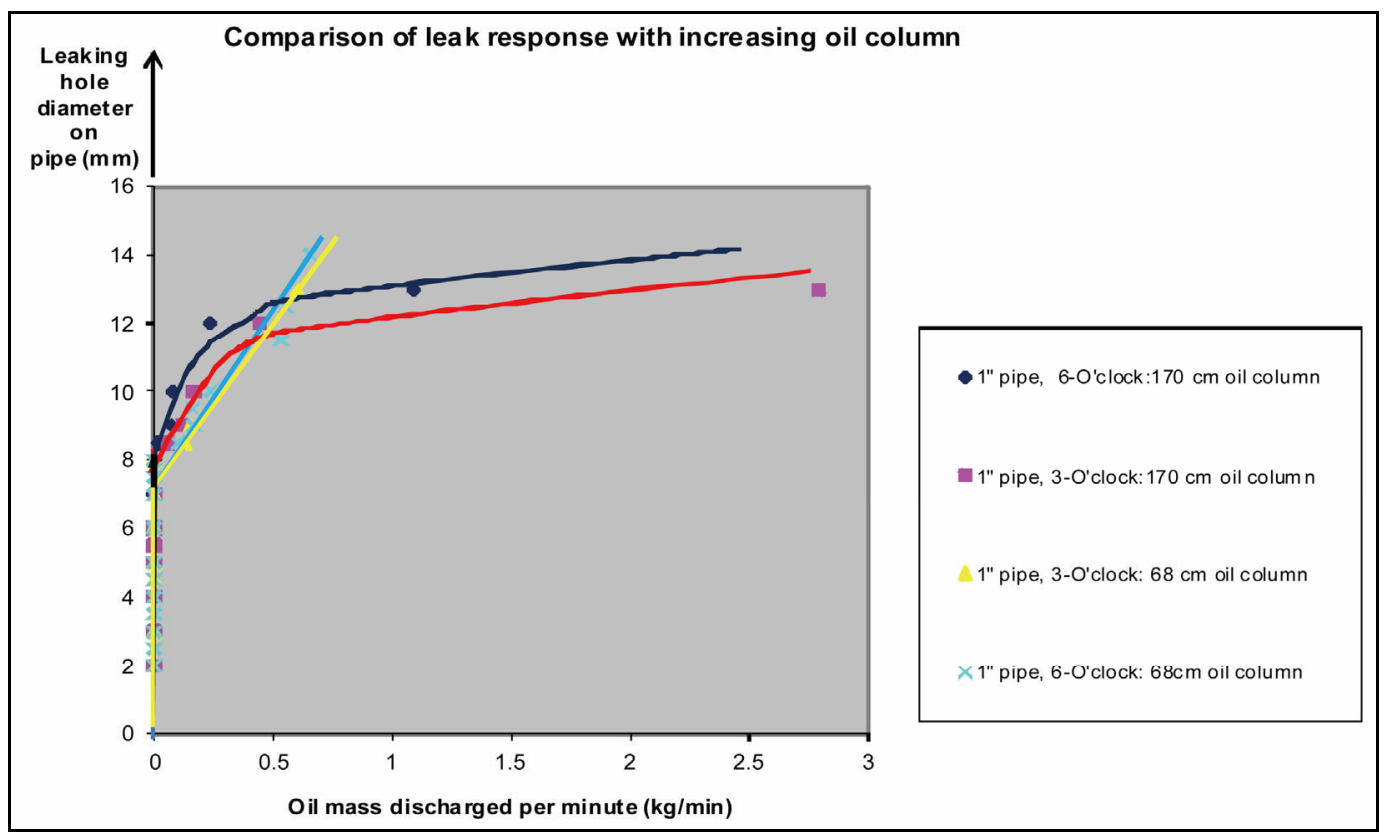

Figure 4. Comparing leak characteristics for varying oil column.

characteristics of the "holding” and "flowing” ranges.

Though within the "flowing range", leak occurs even when the valves are closed. However, the rate is much shallower compared to a fully or partially open position of any of the valves.

3) The effect of loss type 4 was minimized by reducing the riser height. Here, an opening in the range of the "flowing range" was made and the system lowered to the bottom of the water. The water height was $17 \mathrm{~cm}$, the line pipe diameter 1" and the riser height was at minus 12 $\mathrm{cm}$, i.e., $12 \mathrm{~cm}$ below water level. It was observed that intrusion continued.

4) Though it is evident that the 3/8”, 1", 2", 3" and 4" pipelines leaking characteristics show similar trend, minor irregularities, however, are observed in the data. These irregularities are attributed to "hole" drilling procedure. Drill-outs stuck around the edge of the hole and obstructed flow. Inside drill-outs on the pipelines were sometimes difficult to clear. Generally, however, the results are considered fair. 


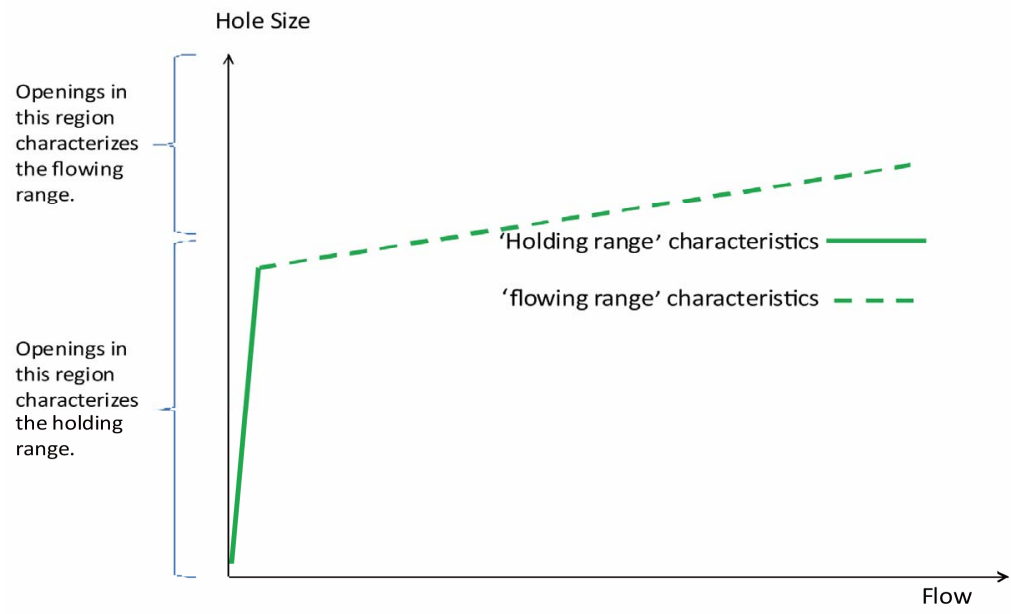

Figure 5. Leak characteristics for holed 3/8”, 1", 2”, 3” and 4" pipelines.

Table 3. Leak characteristics in water.

\begin{tabular}{|c|c|c|c|c|}
\hline $\begin{array}{l}\text { Pipe size (Internal } \\
\text { diameter) }\end{array}$ & $\begin{array}{l}\text { Hole size within the "holding range" } \\
\text { characteristic (with comments) }\end{array}$ & $\begin{array}{l}\text { Hole size within the "flowing range" } \\
\text { characteristic (with comments) }\end{array}$ & $\begin{array}{l}\text { Maximum oil column on } \\
\text { the riser }(\mathbf{c m})\end{array}$ & $\begin{array}{l}\text { Maximum water } \\
\text { depth (cm) }\end{array}$ \\
\hline 3/8” & $\begin{array}{l}\quad 4 \mathrm{~mm} \\
\begin{array}{l}\text { No intrusion process after } 12 \text { hours in } \\
\text { water. }\end{array}\end{array}$ & $\begin{array}{l}10 \mathrm{~mm} \\
\begin{array}{l}\text { Intrusion process observed within } \\
\text { short time. }\end{array}\end{array}$ & 70 & 20 \\
\hline $1 ”$ & $\begin{array}{l}6 \mathrm{~mm} \\
\text { No intrusion process observed. } \\
\text { Pipeline in water for } 13 \text { hours and } \\
30 \text { minutes. }\end{array}$ & $\begin{array}{l}13 \mathrm{~mm} \\
\begin{array}{l}\text { Intrusion process observed within } \\
\text { short time. }\end{array}\end{array}$ & 40 & 16.5 \\
\hline 2" & $\begin{array}{l}4 \mathrm{~mm} \\
\text { No intrusion process observed. } \\
\text { Pipeline in water for } 13 \text { hours and } \\
30 \text { minutes. }\end{array}$ & $\begin{array}{l}12 \mathrm{~mm} \\
\begin{array}{l}\text { Intrusion process observed within } \\
\text { short time. }\end{array}\end{array}$ & 40 & 16 \\
\hline
\end{tabular}

Table 4. Hole interaction test.

\begin{tabular}{cccc}
\hline Pipe size (Internal diameter) & $\begin{array}{c}\text { Hole size within the “holding range” } \\
\text { characteristic }\end{array}$ & $\begin{array}{c}\text { Maximum oil column on the } \\
\text { riser (cm) }\end{array}$ & Maximum water depth (cm) \\
\hline 1 " & $2 \times 5$ mm (separated by 2.5 cm distant). \\
No intrusion process noticed. & 40 & 16.5 \\
\hline
\end{tabular}

The optimum action to minimise spill is closure of upstream valve, followed by the downstream valve. This is because the "early phase" high pressure leak (types 2 and 3 ) occurs within seconds and could drive the flow downstream to receiver, further reducing the pressure within when downstream valve is closed.

For both pipelines on land and in water, proper estimation of oil spills is possible when the leaking opening area is known. The spill estimation method available at present seems inadequate $[9,10]$.

With known characteristic of a pipeline, proper spill estimation may be obtained:

$$
\sum \text { spill }=\sum \text { shutdown loss }+\sum \text { early loss }+\sum \text { late loss }
$$

The third term on right side is zero in the "holding range”.

\section{Conclusions}

Within the "holding range", the leak stops after an "early leak" event, provided the upstream and downstream valves are closed. On the other hand, leaks continued by intrusion process in the "flowing range" after "early leak". In the event of leak, the optimum method of spill emergency control with respect to valves operations is closure of upstream and then downstream valves nearly simultaneously. This conclusion appears to align with recommendations of ASME B31.4.

It is obvious from this test that the correctness of the assumption that oil stops to spill once supply pressure is shut off or its valves closed up is limited to the size of the 
hole on the pipeline. Test shows that such assumption is contestable for leaks occurring in the flowing stage (see Equation (1)).

Future work would be to extend the test to relatively large diameter pipelines, develop mathematical approach to estimate the leak characteristics of pipelines given necessary parameters and in-field verification tests.

\section{Acknowledgements}

We express our gratitude to AS Norske SHELL for provision of fund for the research studies in this subject area. Kjell Traa provided lots of the background information and literatures for this study. We are grateful to Mr. Levi Okoronkwo, and Henry Afambu for the great assistance offered during the laboratory tests. We also acknowledge John Grønli and Samdar Kakay for their assistance in performing the work in the laboratory.

\section{REFERENCES}

[1] The United State's Department of Transportation Pipeline and Hazardous Materials Safety Administration, "Hearing on the ExxonMobil Silvertip Pipeline Failure in Yellowstone County, Montana,” 2011.

[2] S. Nigeria, “Oil Spill Data,” 2011. http://www.shell.com.ng/home/content/nga/environment_ society/respecting_the_environment/oil_spills/

[3] US Department of Transportation Standards, "United State's Environmental Impact Statement (EIS. TransCanada’s Keystone XL Project,” 2010.

http://www.keystonepipeline-xl.state.gov/clientsite/keysto nexl.nsf/19_KXL_Sec_3.13_Risk\%20Assessment.pdf?O penFileResource

[4] T. B. Benjamin, "Gravity Currents and Related Phenomena,” Journal of Fluid Mechanics, Vol. 31, No. 2, 1968, pp. 209-246. doi:10.1017/S0022112068000133
[5] T. K. Fanneløp, "Flow Processes and Leak Rates Associated with Broken Underwater Pipelines," Norwegian Maritime Research, Vol. 5, No. 1, 1977, pp. 6-13.

[6] C. Kranenburg, "Exchange Flow of Oil and Sea Water in a Ruptured Submarine Pipelines," Applied Ocean Research, Vol. 6, No. 1, 1984, pp. 23-30.

[7] J. A. Agbakwuru, "Potential Leak Detection Technologies: Assessment and Perspective in the Nigerian Delta Region," Journal of Environmental Protection, Vol. 2, No. 8, 2011, pp. 1055-1061.

[8] I. Jonas, "Montana Leak May Alter Exxon Safety Reviews,” 2011.

http://www.reuters.com/article/2011/07/04/us-exxon-revi ew-idUSTRE7634WS20110704

[9] H. Rye and P. J. Brandvik, "Verification of Subsurface Oil Spill Models,” 1996.

http://www.iosc.org/papers_posters/02334.pdf

[10] M. Reed, Ø. Johansen, B. Høverstad, B. Hetland, S. Buffington and M. H. Emilsen, "Numerical Model for Estimation of Pipeline Oil Spill Volumes," Environmental Modelling \& Software, Vol. 21, No. 2, 2006, pp. 178-189.

[11] Ø. Johansen, "Development and Verification of DeepWater Blowout Models,” Marine Pollution Bulletin, Vol. 47, No. 9-12, 2003, pp. 360-368. doi:10.1016/S0025-326X(03)00202-9

[12] C. Koh Robert and F. Loh-Nien, "Mathematical Models in the Prediction of Temperature Distribution Resulting from the Discharge of Heated Water into Large Bodies of Water,” EPA Report, 1970.

[13] T. K. Fanneløp, "Hydrodynamics of Underwater Blowouts,” Norwegian Maritime Research, Vol. 4, 1980, pp. 7-33.

[14] T. K. Fanneløp, "Fluid Mechanics for Industrial Safety and Environmental Protection," Industrial Safety Series, Vol. 3, 1994, pp. 59-98. 